\title{
Recurrence factors in patients with Keratinizing squamous metaplasia of the bladder after surgical management: a single-center retrospective study
}

\author{
Zhenglin Yi ${ }^{1 \#}$, Zhenyu Ou${ }^{1 \#}$, Xi Guo ${ }^{2}$, Belaydi Othmane ${ }^{1}$, Jiao Hu${ }^{1}$, Wenbiao Ren ${ }^{1}$, Huihuang Li $^{1}$, \\ Tongchen $\mathrm{He}^{1}$, Dongxu Qiu ${ }^{1}$, Zhiyong Cai ${ }^{1}$, Jinbo Chen ${ }^{1}$, Xiongbing Z ${ }^{1}$ \\ ${ }^{1}$ Department of Urology, Xiangya Hospital, Central South University, Changsha, China; ${ }^{2}$ Department of Urology, Hunan Provincial People's \\ Hospital, Changsha, China \\ Contributions: (I) Conception and design: Z Yi, Z Ou, J Chen, X Zu; (II) Administrative support: Z Ou, X Guo, J Chen, X Zu; (III) Provision of study \\ materials or patients: Z Yi, H Li, D Qiu; (IV) Collection and assembly of data: Z Yi, X Guo, T He, Z Cai; (V) Data analysis and interpretation: Z Yi, \\ B Othmane, J Hu, W Ren; (VI) Manuscript writing: All authors; (VII) Final approval of manuscript: All authors. \\ \#These authors contributed equally to this work. \\ Correspondence to: Xiongbing Zu; Jinbo Chen. Department of Urology, Xiangya Hospital, Central South University, Changsha 410008, China. \\ Email: zuxbxyyy@126.com; chenjinbo1989@yahoo.com.
}

Background: Keratinizing squamous metaplasia (KSM) is a clinically heterogeneous disease that lacks research that provide definitive recurrent risk factors. Therefore, we identified the recurrence factors in patients with KSM of the bladder after transurethral resection (TUR). We also attempted to investigate the association between KSM and bladder cancer.

Methods: Clinical information of 257 patients diagnosed with KSM who underwent TUR in Xiangya Hospital from January 2010 to November 2018 were retrospectively collected. Clinical information was available for follow-up of 223 patients. To determine the risk factors for recurrence, we conducted univariate and multivariate cox regression analysis respectively. To explore the association between KSM and bladder cancer, we used clinical follow-up data.

Results: The median follow-up time is 49 (IQR, 12-121) months. Five-year recurrence-free rate (RFR) and 1 -year RFR were $86.1 \%$ and $91.9 \%$, respectively. Thirty-one patients (13.9\%) relapsed of KSM after a median follow-up of 49 months (range, 12-121 months), and none of them developed subsequent bladder cancer. Univariate Cox analysis indicated that urinary tract infection [hazard ratio $(\mathrm{HR})=2.111$; 95\% confidence interval (CI): 1.043-4.271; P=0.038], and atypical urothelial hyperplasia of the bladder $(\mathrm{HR}=4.191 ; 95 \%$ CI: 2.006-8.756; $\mathrm{P}<0.001)$ were significant recurrence factors. Multivariate Cox analysis suggested that atypical urothelial hyperplasia of the bladder $(\mathrm{HR}=3.506 ; 95 \% \mathrm{CI}: 1.663-7.392 ; \mathrm{P}=0.001)$ was the independent risk factor for postoperative recurrence of KSM.

Conclusions: The recurrence rate in patients with KSM was about $13.9 \%$, and atypical urothelial hyperplasia of the bladder was the independent risk factor in patients with KSM recurrence. In cases with bladder atypical urothelial hyperplasia, close follow-ups are necessary. Also, we demonstrated that KSM did not increase the subsequent risk of bladder cancer.

Keywords: Atypical urothelial hyperplasia; recurrence; squamous metaplasia; transurethral resection (TUR)

Submitted Jun 16, 2020. Accepted for publication Dec 11, 2020.

doi: $10.21037 /$ tau-20-948

View this article at: http://dx.doi.org/10.21037/tau-20-948 


\section{Introduction}

Keratinizing squamous metaplasia (KSM), also called leukoplakia of bladder or keratinizing cystitis of the bladder, is a clinically heterogeneous disease. KSM is a rare disease, with its reported incidence being 1:10,000 $(1,2)$. Moreover, the improvement of cystoscopy and pathological examination technology caused the incidence of KSM to increase in recent years (3). Pathologically, the normal bladder urothelium is replaced by the keratinizing squamous epithelium (4). The clinical manifestations of vesical leukoplakia are mainly bladder stimulation symptoms, such as frequent urination, urgency, urination pain, hematuria and urinary tract obstruction (3).

The pathogenesis of KSM remains incompletely understood. Clinically, the disease was found to be closely related to long-term stimulation, such as lower urinary tract infection, obstruction, proliferative lesions, chronic cystitis, and long-term indwelling catheters $(2,5)$. Our recent study identified independent risk factors for cystitis glandular (CG) recurrence to be urinary tract infection, long-term indwelling catheter, urinary stone, squamous metaplasia, and atypical urothelial hyperplasia (6). KSM is now generally considered a pre-malignant lesion. According to some case reports, the clinical statistics of its malignant transformation rate is $15 \sim 20 \%$ (7). Transurethral resection (TUR) or fulguration for the total removal of the affected mucosa and close follow-ups were widely used as treatment strategies $(3,8)$. However, some patients suffer from KSM recurrence after receiving surgical management. Due to the disease's rarity, no literature has focused on the risk factors for KSM recurrence after surgical management. This study aims to retrospectively analyze potential recurrence factors in patients with KSM after surgical management in a single center with 223 patients, and investigate the association between KSM and bladder cancer. We present the following article in accordance with the STROBE reporting checklist (available at http://dx.doi.org/10.21037/tau-20-948).

\section{Methods}

\section{Study design}

This single-center retrospective study was approved by the hospital institutional review board. Patients with KSM of the bladder underwent TUR in the Department of Urology, Xiangya Hospital of Central South University, were consecutively selected from January 2010 to November 2018, and accomplished the following standards: (I) the primary lesion was treated by the surgical method; (II) the postoperative pathological diagnosis of all patients was confirmed as KSM by experienced pathologists. Poor quality and non-surgically obtained specimens were excluded. Two hundred fifty-seven patients were identified, and 34 patients were excluded because they lacked follow-up data, which resulted in just 223 patients included in the study cohort. The study was conducted in accordance with the Declaration of Helsinki (as revised in 2013). The study was approved by ethics board of Xiangya Hospital, Central South University (No. 201803086) and informed consent was taken from all the patients.

\section{Data collection}

Epidemiological data acquired from the electronic medical record system (EMRs) included clinical characteristics (sex, age, smoking status, main symptoms, and urological history), as well as leukoplakia and treatment-related data (leukoplakia location, leukoplakia size, the characteristics of pathology, and extent of resection). The Urological history incorporated the history of urinary tract infection, lower urinary tract obstructions and disease course of KSM [from the first symptom(s) until surgical management].

\section{Study outcomes}

The main outcome was to determine postoperative recurrence factors in KSM patients. The minor outcome was to investigate the association between KSM and bladder cancer. Relapse was defined as the occurrence of cystoscopy that revealed primary lesions or neoplasms and a biopsy that confirmed KSM. Lesions' histological type was evaluated according to the most updated 2016 WHO classification criteria (9).

\section{Pathological features}

All cases of histological type were examined against histological criteria by an experienced genitourinary pathologist. On microscopy, the normal bladder urothelium is replaced by stratified squamous epithelium. KSM showed a keratinized layer covering the thickened non-tumor squamous epithelium (Figure 1). In some cases of KSM, benign and atypical urothelial hyperplasia had adjacent lesion areas within the mucosa (Figure 2).

\section{The follow-ups}

The last follow-up was in December 2019. Postoperative 


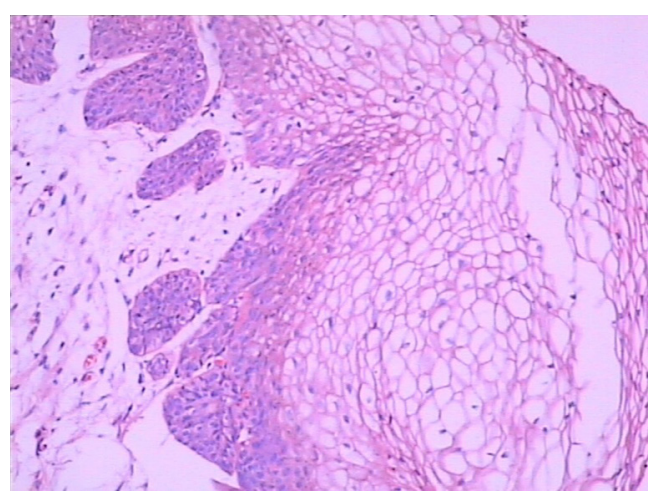

Figure 1 Keratinized squamous metaplasia with a granular surface and a thick layer of keratin. Keratin on the surface forms the plaque of leukoplakia. HE $\times 100$.

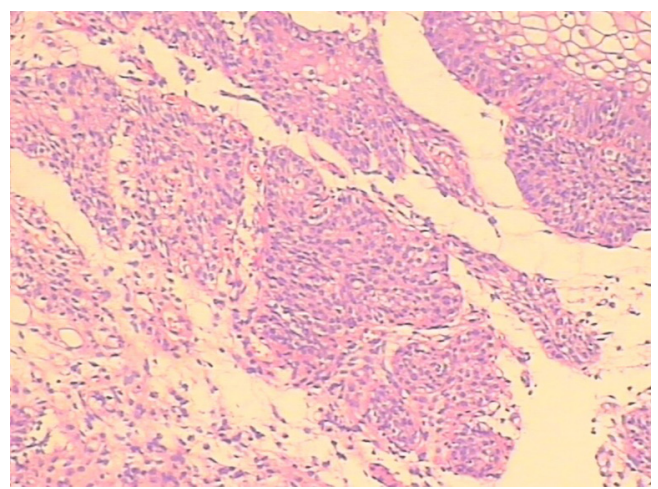

Figure 2 Atypical urothelial hyperplasia is characterized by disordered nuclear enlargement, hyperchromatism, irregular nuclear membrane, cellular pleomorphism, and loss of polarity. $\mathrm{HE} \times 100$.

follow-up was conducted either by a telephone interview or an outpatient visit. To ensure the early discovery of relapses, patients were followed up annually. The contents of the follow-ups included history taking, urinalysis and urine culture, uroflowmetry, abdominal Doppler ultrasound, cystoscopy, and histological biopsy. The histological biopsy was reserved for when cystoscopy detected a suspected recurrence, indications of recurrence, recurrence or malignant transformation time and survival time.

\section{Statistical analysis}

SPSS software was used to analyze all the data, version 26.0 (SPSS Inc., Chicago, Illinois, USA). All continuous variables were converted to categorical variables for statistical analysis. Patients were censored when recurrence did not occur at the last time of follow-up. To determine the risk factors for postoperative recurrence, we conducted a univariate cox regression analysis. To identify independent risk factors for postoperative recurrence in patients with KSM, multivariate Cox regression analysis was used. We used the Kaplan-Meier method to plot the recurrencefree rate (RFR) curves and the log-rank test to examine the differences. $\mathrm{P}$ value of less than 0.05 was supposed to statistically significant.

\section{Results}

Table 1 shows the demographic and baseline characteristics of the 223 patients. All patients were female. Their average age was $39.6 \pm 9.8$ years. Of these patients, $25(11.2 \%)$ were diagnosed with lower urinary tract obstruction. The percentage of patients with vesical leukoplakia located in the trigone of the bladder and patients with it located elsewhere in the bladder was 175 (78.5\%) and 48 (21.5\%), respectively. In the postoperative pathological results, 28 (12.6\%) patients were diagnosed with KSM complicated with atypical urothelial hyperplasia, and 195 (87.4\%) patients were diagnosed with simple KSM. One hundred and two $(45.7 \%)$ patients were diagnosed with urinary tract infections, $121(54.3 \%)$ patients reported no urinary tract infections. After a median follow-up of 49 (IQR, 12-121) months, 31 patients relapsed of KSM. No malignant transformation case was found during the follow-up period, and none of the patients died. Five-year RFR and 1-year RFR were $86.1 \%$ and $91.9 \%$, respectively (Figure 3).

Univariate Cox analysis revealed that urinary tract infection and atypical urothelial hyperplasia of the bladder were significant recurrence factors (Table 2). The $\mathrm{P}$ values were 0.038 (hazard ratio $=2.111 ; 95 \%$ confidence interval: $1.043-4.271$ ) and $<0.001$ (HR $=4.191$; $95 \%$ CI: $2.006-$ 8.756), respectively. Multivariate Cox analysis revealed that atypical urothelial hyperplasia of the bladder was the independent predictive factor of recurrence. The $\mathrm{P}$ value was 0.001 (HR $=3.506$; 95\% CI: 1.663-7.392). Five-year RFR and 1-year RFR of patients with atypical urothelial hyperplasia $v s$. no atypical urothelial hyperplasia was $60.7 \%$ vs. $89.7 \%$ and $82.1 \%$ vs. $92.8 \%$, respectively (Figure 4).

\section{Discussion}

Keratinized squamous metaplasia has been considered a rare disease in the bladder. However, according to two Chinese 
Table 1 Demographic and baseline characteristics of patients with KSM

\begin{tabular}{lcc}
\hline Characteristics & Value & $\%$ \\
\hline $\mathrm{N}$ & 223 & $100 \%$ \\
Age (years) & $39.6 \pm 9.8$ & \\
$>40$ & 116 & 52.018 \\
$\leq 40$ & 107 & 47.982 \\
Smoking status & & \\
Smoker & 7 & 3.139 \\
Nonsmoker & 216 & 96.861 \\
The course of the disease (months) & $39.4 \pm 61.9$ & \\
$>3$ & 162 & 72.646 \\
$\leq 3$ & 61 & 27.354
\end{tabular}

Urinary tract infection

$\begin{array}{lll}\text { Yes } & 102 & 45.740 \\ \text { No } & 121 & 54.260\end{array}$

Lower urinary tract obstruction

$\begin{array}{lcc}\text { Yes } & 25 & 11.211 \\ \text { No } & 198 & 88.789\end{array}$

Distribution of the size of vesical leukoplakia

$\begin{array}{lcr}>1 \mathrm{~cm} & 190 & 85.202 \\ \leq 1 \mathrm{~cm} & 33 & 14.798\end{array}$

Distribution of the location of vesical leukoplakia

$\begin{array}{lcc}\begin{array}{l}\text { Trigone of bladder } \\ \text { Other bladder parts }\end{array} & 48 & 78.475 \\ \text { Extent of resection } & 21.525 \\ \begin{array}{l}\text { Beyond the edge of vesical } \\ \text { leukoplakia }>2 \mathrm{~cm}\end{array} & 95 & 42.601 \\ \begin{array}{l}\text { Beyond the edge of vesical } \\ \text { leukoplakia } \leq 2 \mathrm{~cm}\end{array} & 128 & 57.399 \\ \begin{array}{l}\text { Distribution of pathology } \\ \text { Atypical urothelial hyperplasia }\end{array} & 28 & 12.556 \\ \text { No atypical urothelial hyperplasia } & 195 & 87.444\end{array}$

KSM, keratinizing squamous metaplasia.

studies, in 2005 and 2006, the rate of diagnosing vesical leukoplakia by cystoscopy in two urology departments was $8.7 \%$ and $7.3 \%$, respectively $(10,11)$. This suggests that the disease may not be as rare as reported in the literature.

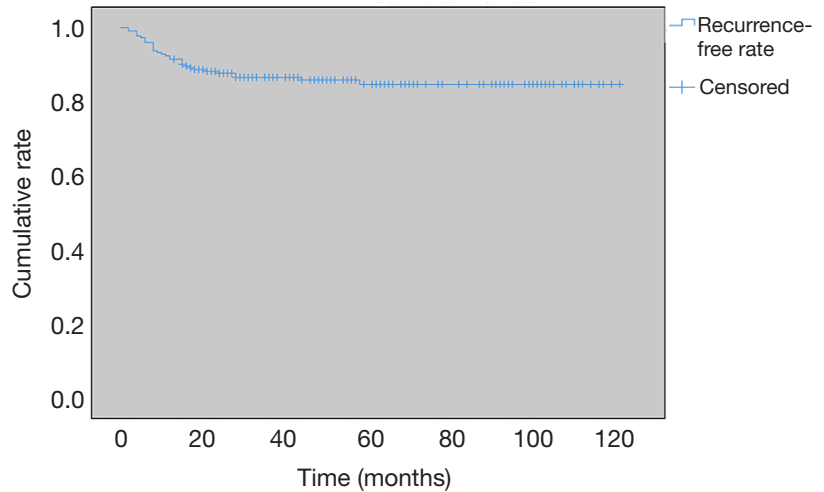

Figure 3 Recurrence-free rate of the patients over time measured by the Kaplan-Meier method.

In 2002, KSM was designated as a presumed preneoplastic condition by the Consultation on the Diagnosis of NonInvasive Urothelial Neoplasms (12). It is generally believed that squamous metaplasia may progress to squamous cell carcinoma. Patients with KSM often have a variety of urinary symptoms, and studies have shown that the quality of life in patients with KSM was affected by lower urinary tract symptoms, as well as them being more prone to anxiety and depression $(13,14)$. As the etiology of the disease is unknown, there are no effective treatments until now. Currently, TUR is the main treatment for vesical leukoplakia used in clinical practice $(3,8)$. However, some patients with KSM are prone to relapse after surgery. Consequently, it is important to analyze the risk factors for postoperative recurrence of KSM. Here, we have demonstrated that urinary tract infection and atypical urothelial hyperplasia of the bladder were associated with the poor RFR of KSM by univariate analysis. Atypical urothelial hyperplasia of the bladder was the independent recurrence factor remaining statistically significant by multivariable analysis.

So far, few types of research have been done on this disease, according to the literature. Most of the available publications are reviews and case reports. It is worth mentioning that khan conducted a 54-year retrospective study in 2002. In the study, most of the cases were male. He indicated that the appearance of KSM might be localized or disseminated. The localized lesion is favorable since most patients with limited lesions did not progress after TUR. There were only 2 patients with KSM who eventually developed bladder cancer. On the contrary, disseminated keratinization of the bladder is dangerous and may increase 
Table 2 Univariate and multivariate Cox analyses of factors predicting the recurrence of KSM

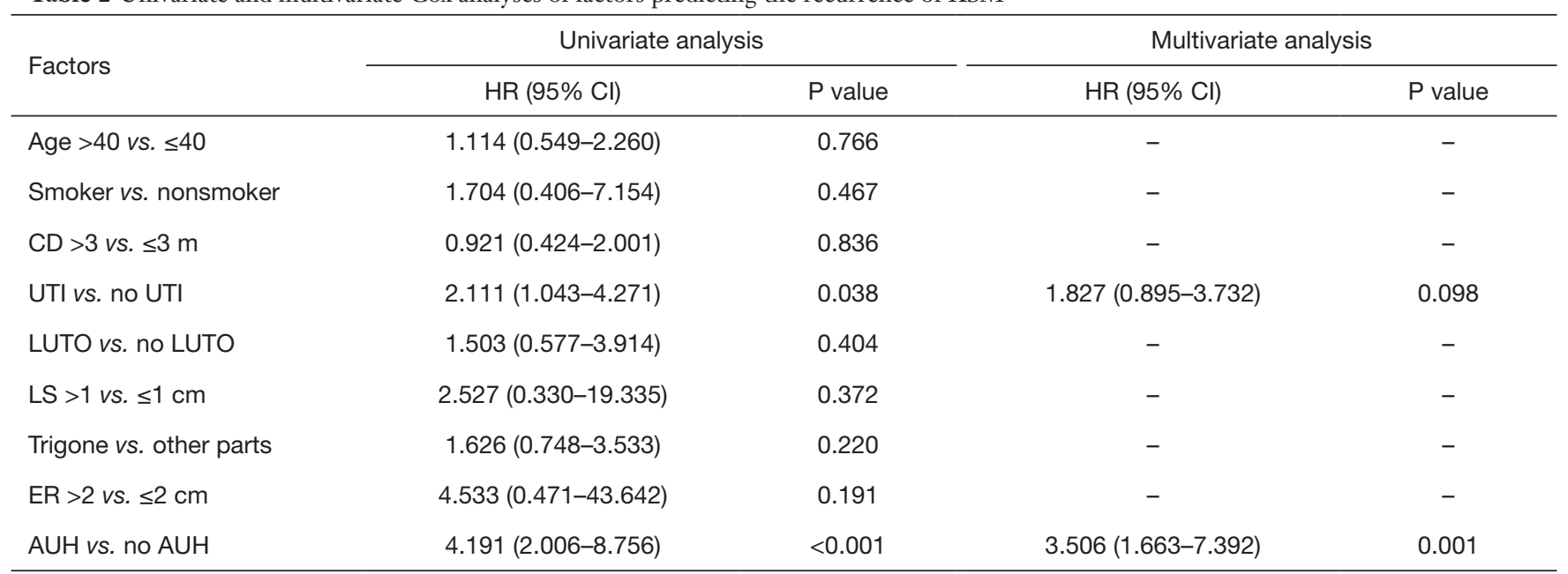

KSM, keratinizing squamous metaplasia; CD, course of the disease; UTI, urinary tract infection; LUTO, lower urinary tract obstruction; LS, leukoplakia size; ER, extent of resection; AUH, atypical urothelial hyperplasia.

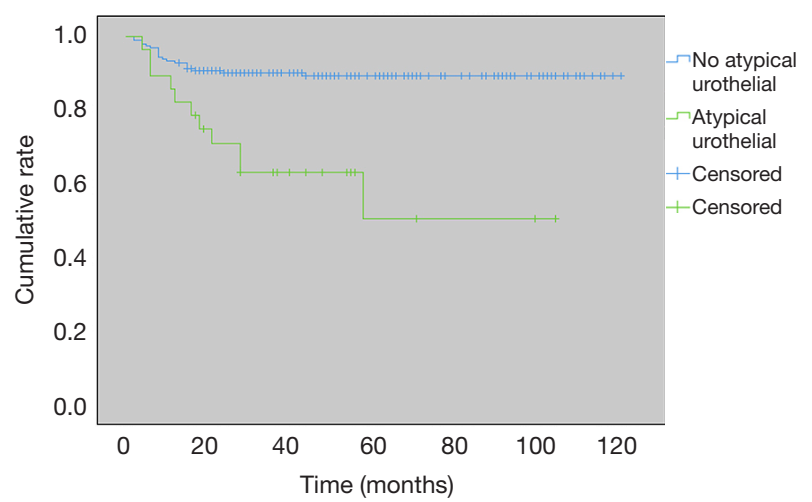

Figure 4 Recurrence-free rate of the patients with atypical urothelial hyperplasia $v s$. no atypical urothelial hyperplasia over time measured by the Kaplan-Meier method.

the subsequent risk of bladder cancer (2). Staack et al. found that TP53 mutation rates in KSM patients were similar to those in healthy subjects $(16.7 \%$ vs. $14.3 \%)$ and significantly lower than in bladder cancer patients (39.9\%) (15). The disease has previously been reported to affect more males than females $(2,16)$. However, in our study, all KSM patients were females, which may be related to ethnic differences. This may indicate that in the Chinese population, the proportion of women suffering from this disease is much higher than that of men. But the reasons need to be further studied. In our study, no patients with malignant transformation have been found during followup. All patients had localized lesions under cystoscopy, and their biopsies showed Keratinized squamous metaplasia. This might be why no cases of malignant transformation were found during the follow-ups.

Compared with lower urinary tract obstruction, surgical range, size, and location of leukoplakia, urinary tract infection was a more significant risk factor for the recurrence of KSM. In the present study, univariate analysis showed that urinary tract infection was an important factor affecting the recurrence of KSM. However, it was not an independent risk factor for postoperative recurrence of KSM after multivariate analysis. This is mainly because not all irritation to the bladder is caused by infection, but some are partly due to calculi, urinary tract obstruction, and proliferative lesions $(2,5)$.

Due to this disease's rarity, level-1 evidence is lacking to prove that it is a premalignant lesion, but based on the available studies, close annual monitoring of cystoscopy is recommended as grade C (17). The results of this study showed that by univariate and multivariate Cox analysis, atypical urothelial hyperplasia of the bladder was the most important risk factor for postoperative recurrence of KSM. Therefore, to reduce the recurrence rate of KSM and ensure early discovery of tumors, we recommend semi-annual cystoscopy and multiple biopsies when initial pathology reveals evidence of atypical urothelial hyperplasia (18). We also propose TUR for a limited lesion in patients with recurrence.

This study has some limitations. First, the study's sample was relatively small. Secondly, some risk factors for 
recurrence may not be included, such as a positive surgical margin. Third, retrospective studies are biased. Despite the scientific limitations of this study, we believe that the findings of this study have important implications for the surgical treatment and follow-up of KSM. However, more large prospective studies are needed to confirm this.

\section{Conclusions}

Atypical urothelial hyperplasia of the bladder is the independent risk factor in patients with KSM recurrence after surgical management. For patients at high risk of atypical urothelial hyperplasia, more frequent and closer follow-ups, including cystoscopy and biopsy, should be recommended to reduce the risk of recurrence and malignancy. Also, we demonstrated that KSM did not increase the subsequent risk of bladder cancer.

\section{Acknowledgments}

We sincerely thank Belaydi Othmane for editing the language of this article.

Funding: This study was supported by the National Natural Science Foundation of China (grant numbers 81873626, 81902592), Hunan Province Key R\&D Program (2019SK2202), the Hunan Province Funds for Distinguished Young Scientists of China (2016JJ1026), Hunan Province Technology Innovation Guidance Program - Clinical Medical Technology Innovation Guidance Project No. 2018SK51714, and Xiangya Hospital Youth Fund (2018Q09).

\section{Footnote}

Reporting Checklist: The authors have completed the STROBE reporting checklist. Available at http://dx.doi. org/10.21037/tau-20-948

Data Sharing Statement: Available at http://dx.doi. org/10.21037/tau-20-948

Peer Review File: Available at http://dx.doi.org/10.21037/ tau-20-948

Conflicts of Interest: All authors have completed the ICMJE uniform disclosure form (available at http://dx.doi. org/10.21037/tau-20-948). XZ serves as an unpaid editorial board member of Translational Andrology and Urology. The other authors have no conflicts of interest to declare.

Ethical Statement: The authors are accountable for all aspects of the work in ensuring that questions related to the accuracy or integrity of any part of the work are appropriately investigated and resolved. The study was conducted in accordance with the Declaration of Helsinki (as revised in 2013). The study was approved by ethics board of Xiangya Hospital, Central South University (No. 201803086) and informed consent was taken from all the patients.

Open Access Statement: This is an Open Access article distributed in accordance with the Creative Commons Attribution-NonCommercial-NoDerivs 4.0 International License (CC BY-NC-ND 4.0), which permits the noncommercial replication and distribution of the article with the strict proviso that no changes or edits are made and the original work is properly cited (including links to both the formal publication through the relevant DOI and the license). See: https://creativecommons.org/licenses/by-nc-nd/4.0/.

\section{References}

1. Connery DB. Leukoplakia of the urinary bladder and its association with carcinoma. J Urol 1953;69:121-7.

2. Khan MS, Thornhill JA, Gaffney E, et al. Keratinising squamous metaplasia of the bladder: natural history and rationalization of management based on review of 54 years experience. Eur Urol 2002;42:469-74.

3. Ahmad I, Barnetson RJ, Krishna NS. Keratinizing squamous metaplasia of the bladder: a review. Urol Int 2008;81:247-51.

4. McKenney JK. Precursor lesions of the urinary bladder. Histopathology 2019;74:68-76.

5. Clouston D, Lawrentschuk N. Metaplastic conditions of the bladder. BJU Int 2013;112 Suppl 2:27-31.

6. $\mathrm{Hu} \mathrm{J}, \mathrm{Li} \mathrm{C}, \mathrm{Guo} \mathrm{X}$, et al. Development and validation of a predictive nomogram for the risk of recurrence in patients with cystitis glandularis. Ann Transl Med 2020;8:352.

7. Gumus E, Yilmaz B, Miroglu C. Extensive bilateral renal pelvis, ureter and bladder leukoplakia. Int J Urol 2002;9:653-5.

8. Ozbey I, Aksoy Y, Polat O, et al. Squamous metaplasia of the bladder: findings in 14 patients and review of the literature. Int Urol Nephrol 1999;31:457-61. 
9. Epstein JI, Amin MB, Reuter VR, et al. The World Health Organization/International Society of Urological Pathology consensus classification of urothelial (transitional cell) neoplasms of the urinary bladder. Bladder Consensus Conference Committee. Am J Surg Pathol 1998;22:1435-48.

10. Tang $X, Y e Z$, Tang $M$. The clinical features and diagnosis of vesical leukoplakia. J Clin Surg 2005;13:734-5.

11. Tang $X, Y e Z$, Tang $M$, et al. Clinical diagnosis of vesical leukoplakia. J Clin Urol 2006;21:353-4.

12. Lopez-Beltran A, Cheng L, Andersson L, et al. Preneoplastic non-papillary lesions and conditions of the urinary bladder: an update based on the Ancona International Consultation. Virchows Arch 2002;440:3-11.

13. Lee KS, Yoo TK, Liao L, et al. Association of lower urinary tract symptoms and $\mathrm{OAB}$ severity with quality of life and mental health in China, Taiwan and South Korea: results from a cross-sectional, population-based study.

Cite this article as: $\mathrm{Yi} Z$, Ou Z, Guo X, Othmane B, Hu J, Ren W, Li H, He T, Qiu D, Cai Z, Chen J, Zu X. Recurrence factors in patients with Keratinizing squamous metaplasia of the bladder after surgical management: a single-center retrospective study. Transl Androl Urol 2021;10(2):734-740. doi: 10.21037/tau20-948
BMC Urol 2017;17:108.

14. Quaghebeur J, Wyndaele JJ. Prevalence of lower urinary tract symptoms and level of quality of life in men and women with chronic pelvic pain. Scand J Urol 2015;49:242-9.

15. Staack A, Schlechte H, Sachs M, et al. Clinical value of vesical leukoplakia and evaluation of the neoplastic risk by mutation analyses of the tumor suppressor gene TP53. Int J Urol 2006;13:1092-7.

16. Benson RC Jr, Swanson SK, Farrow GM. Relationship of leukoplakia to urothelial malignancy. J Urol 1984;131:507-11.

17. Amin MB, McKenney JK, Paner GP, et al. ICUD-EAU International Consultation on Bladder Cancer 2012: Pathology. Eur Urol 2013;63:16-35.

18. Kasianandan A, Kannan K. Leukoplakia of the bladder: a case report and literature review. Int Urogynecol J 2012;23:131-3. 